\title{
Isolation and identification of infectious bursal disease virus from broiler and layer chickens during the outbreak year 2007 in Bangladesh
}

\author{
Md. Taohidul Islam ${ }^{1,2}$, Mohammad Mohiuddin ${ }^{1}$, Muhammad Tofazzal Hossain ${ }^{1}$, \\ Md. Bahanur Rahman', Md. Mostafizur Rahman', Md. Siddiqur Rahman², \\ Hee-Jong Song ${ }^{3}$, Md. Alimul Islam ${ }^{1}$. \\ ${ }^{1}$ Department of Microbiology and Hygiene, ${ }^{2}$ Department of Medicine, Faculty of Veterinary Science, \\ Bangladesh Agricultural University, Mymensingh 2202, Bangladesh \\ ${ }^{3}$ Korea Zoonoses Research Institute, Chonbuk National University, Jeonju 561-756, Korea
}

(Received 6 September 2011; revised 12 March 2012; accepted 20 March 2012)

\section{Abstract}

The objective of the present study was to isolate and identify infectious bursal disease viruses (IBDVs) from broiler and layer chickens of outbreaks of infectious bursal disease (IBD) in three districts of Bangladesh. A total of 70 bursal samples were collected from dead broiler $(n=40)$ and layer $(n=30)$ chickens showing specific lesions of IBD from seven commercial poultry farms of three different districts (Mymensingh, Chittagong and Tangail) of Bangladesh during the year 2007. Five representative bursal samples from each farm were used for the isolation of IBDVs using 9-day-old embryonated eggs of seronegative flock of layer birds and for identification the samples were subjected to agar gel immunodiffusion test (AGIDT), immunohistochemistry (IHC) and reverse transcription-polymerase chain reaction (RT-PCR). Out of 35 bursal samples, IBDVs were successfully isolated from $28(80 \%)$ samples. By AGIDT, 32 (91.4\%) samples were found positive for IBDV antigen. Results of AGIDT clearly indicated that IBDVs detected in 29 bursal samples of six affected farms were identical to each other but not to IBDVs present in the remaining three samples of another farm. Indirect immunoperoxidase staining of the bursal sections revealed the presence of IBDV antigen in $32(91.4 \%)$ samples and the IBDV antigen was detected mainly in the cortex of the lymphoid follicles of the bursal tissues. In histopathology, cell depletion, atrophy and necrosis were observed in many bursal follicles with severe edema of interfollicular septa. Of the 35 bursal samples, 34 (97.1\%) samples generated 254 bp product by RT-PCR. In conclusion, the results of virus isolation and identification by AGIDT, IHC and the analysis of viral genome by RT-PCR confirmed the outbreaks of acute IBD in commercial poultry of Bangladesh. Moreover, histopathological findings and results of AGIDT gave a clear indication that the isolates from six outbreaks were different from classical strain and it seems to be of very virulent strain. On the other hand, the isolates from the other outbreak were similar to the classical strain.

Key words : Infectious bursal disease virus, Isolation, Immunohistochemistry, RT-PCR

\section{INTRODUCTION}

Infectious bursal disease virus (IBDV) is a causative agent of a highly contagious disease of young chickens (Infectious bursal disease, commonly known as Gumboro

\footnotetext{
*Corresponding author: Md. Alimul Islam, Tel. +88-091-67401-7(Ext.
} 2380), Fax. +88-091-61510, E-mail. alim_bau@yahoo.co.in disease) characterized mainly by severe changes in the bursa of Fabricius followed by immunosuppression (Faragher et al, 1974; Islam et al, 2005). IBDV is a non-enveloped icosahedral double-stranded RNA (dsRNA) virus with a diameter of about 55 60 $\mathrm{nm}$ belongs to the genus Avibirnavirus in the family Birnaviridae (Leong et al, 2000). The dsRNA genome consists of 
two segments, namely, A and B (Müller et al, 1979). The smaller segment (segment B), with a length of about 2,900 bp, encodes the multifunctional protein VP1 of 90-kDa with RNA-dependent RNA polymerase (Spies et al, 1987). The larger segment (segment A) at about $3,200 \mathrm{bp}$ in length, encodes a polyprotein that is cleaved by autoproteolysis to form mature viral proteins VP2, VP3 and VP4 (Hudson et al, 1986). The VP2 and VP3 are the major structural proteins of the virion which are responsible for the regulation of pathogenicity and immunogenicity.

There are two distinct serotypes of IBDV, designated as serotype 1 and serotype 2 (Jackwood and Saif, 1987). All subtypes of serotype 1 strains are pathogenic to chickens and vary markedly in their virulence, whereas, all known subtypes of serotype 2 are non-pathogenic for both turkeys and chickens (Jackwood et al, 1985). According to antigenic variation and virulence property, IBDVs of serotype 1 can be divided into classical virulent (mild, intermediate and intermediate-plus/hot strains), very virulent (vv) and antigenic variant strains. Recently emerged vvIBDV can cause up to $70 \%$ or higher mortality in the field (Chettle et al, 1989; Van den Berg et al, 1991).

IBD has been considered as an existing threat to the poultry industry in Bangladesh since the first isolation of IBDV strain by Rahman et al (1996) from bursa of Fabricius of layer chickens during the period of 19921993. Since then, the disease was satisfactorily controlled by routine vaccination with imported live-attenuated and inactivated IBDV vaccines in Bangladesh. However, outbreaks of acute IBD noticed in 1999 and continued thereafter sporadically (Islam et al, 2001; Islam and Samad, 2003). The emergence of vvIBDV strains among the poultry population of Bangladesh was confirmed by Islam et al(2001). In 2007, many outbreaks of acute IBD were observed both in vaccinated and non-vaccinated broiler and layer flocks in different parts of the country. It is not quite unexpected that high mutation rate of IBDV, segmented nature of the IBDV genome and high immune selection pressure due to intensive vaccination can lead to the emergence of IBDV with new properties (Müller et al, 2003; Jackwood and Sommer-Wagner, 2005). Therefore, it is essential to iso- late, identify and characterize IBDVs when there is any outbreak.

The present study describes the isolation and identification of IBDV from broiler and layer chickens of recent outbreaks of IBD in three districts of Bangladesh.

\section{MATERIALS AND METHODS}

\section{Reference IBDV}

The vaccine strains Nobilis ${ }^{\mathrm{R}}$ Gumboro 228E (Intervet International, Netherlands) and BAU 404 of classical strain (DLS, Dhaka, Bangladeshi) were used as reference IBDVs in agar gel immunodiffusion (AGIDP) test and reverse transcription-polymerase chain reaction (RT-PCR) assay.

\section{Field bursal samples}

Bursal samples of dead birds showing specific lesions of IBD were collected from seven field outbreaks (four in broiler farms and three in layer farms) during the year 2007 from Mymensingh, Chittagong and Tangail districts. From each outbreak of IBD, 10 bursal samples were collected. A portion of each bursal sample was preserved at $-86^{\circ} \mathrm{C}$ while another portion was kept in $10 \%$ buffered normal saline for histopathology and immunohistochemistry. Bursal suspension preserved at the Department of Microbiology and Hygiene, BAU, Mymensingh which were previously confirmed negative for IBDV by AGIDT and RT-PCR were used as negative control.

\section{Inoculation of bursal samples into embryo- nated chicken eggs}

Five representative bursal samples from each outbreak were homogenized with sea sand and $20 \%$ bursal homogenates were prepared in phosphate buffered saline (PBS). After centrifugation of the suspension at 3,000 rpm for $15 \mathrm{~min}$, the supernatants were treated with penicillin $(10,000 \mathrm{IU} / \mathrm{ml})$ and streptomycin $(10,000 \mu \mathrm{g} / \mathrm{ml})$, which were used as inoculum. $0.2 \mathrm{ml}$ of each sample 
was inoculated into 9-day-old embryonated chicken eggs through chorioallantoic membrane (CAM). The eggs were collected from seronegative layer birds of 68 to 70 weeks old. Five embryonated eggs were used for each sample. Allantoicfluids, CAM and the embryo proper were harvested aseptically from the embryonated eggs dying after $24 \mathrm{hr}$ and within 5 days after inoculation and were stored at $-86^{\circ} \mathrm{C}$ until used. Embryos were processed to make $50 \%$ suspensions for the extraction of viral RNA.

\section{Hyperimmune sera preparation}

Hyperimmune sera for using in agar gel immunodiffusion test and immunohistochemistry were raised in 3-week-old cockerels against the intermediate plus IBDV vaccine strain (Nobilis ${ }^{\circledR}$ Gumboro 228E, Intervet International, Netherlands). Six chickens were immunized with the vaccine intraocularly at weekly interval for four occasions. After 10 days of last vaccination, the chickens were bled and sera were separated following the method as described earlier (Jackwood and Saif, 1987). Similarly, chicken anti-NDV serum was also prepared with F-strain of Newcastle disease virus (Baby Chick Ranikhet Disease Vaccine, DLS, Dhaka, Bangladeshi). The prepared hyperimmune sera were aliquoted into $1 \mathrm{~mL}$ volume and stored at $-20^{\circ} \mathrm{C}$ until used.

\section{AGIDT}

The test was performed following the procedures described by Wood et al(1979). Briefly, the central well of a glass slide coated with melted agarose gel was loaded with known hyperimmune sera against IBDV and peripheral wells with reference antigen of IBDVs and bursal suspensions. Slides were kept in moist chamber for 48-72 hours at $4^{\circ} \mathrm{C}$ and observed for antigen antibody reaction in the form of precipitation lines between the central and peripheral wells.

\section{Immunohistochemical detection of IBDV}

Immunohistochemistry (IHC) was performed with slight modifications following the procedures as de- scribed by Tanimura et al(1995). Formalin fixed bursal tissues were embedded in paraffin and 5-micron-thick sections were cut using a sliding microtome (MIC 509, Euromex, Japan) and mounted on glass slides. The sections were deparaffinized twice for 5-minute treatments in $100 \%$ xylene and hydrated through a series of descending graded ethanols (twice for 3-minute treatments in $100 \%$ ethanol and once for 3-minute treatment each in $95 \%, 90 \%, 80 \%$ and $70 \%$ ethanols) at room temperature. Hydrated samples were rinsed in distilled water and reacted with 5\% formaldehyde in PBS for $30 \mathrm{~min}$ instead of $0.3 \%$ hydrogen peroxide in $99.6 \%$ methanol for fixation. Then the samples were rinsed with PBS and treated with $1 \% \mathrm{NP} 40$ in PBS for $1 \mathrm{hr}$ at room temperature instead of $0.1 \%$ actinase $\mathrm{E}$. The samples were washed with PBS and blocked with $2 \%$ normal rabbit serum (Biosource, Camarillo, California, USA) for $2 \mathrm{hr}$ at room temperature. Serum was blotted and slides were incubated overnight with undiluted chicken anti-IBDV hyperimmune serum in a humid chamber at $4^{\circ} \mathrm{C}$. The slides were then washed in PBS and reacted for $1 \mathrm{hr}$ with HRP-conjugated rabbit anti-goat $\operatorname{IgG}(1$ : 500) (Bethyl Lab., Inc., USA) diluted in PBS. After washing in PBS, the sections were incubated for $5 \mathrm{~min}$ in $0.02 \%$ diaminobenzidine tetrahydrochloride dihydrate (AppliChem, Darmstadt, Germany) in Tris-HCl buffer ( $\mathrm{pH}$ 7.6) supplemented with $0.03 \%$ hydrogen peroxide. The slides were then washed with tap water for $5 \mathrm{~min}$, counter stained with hematoxylin, dehydraded through ascending graded ethanols $(70 \%, 80 \%, 90 \%, 95 \%$ and $100 \%$ ) and cleared with xylene, and mounted with DPX for microscopic examination.

\section{Histopathology}

One or two tissue sections of each bursal sample were stained with hematoxylin and eosin according to the procedures as described by Luna(1968).

\section{Extraction of viral RNA}

The genomic viral RNA of IBDV was extracted from the reference IBDVs, bursal as well as embryo suspensions using the QIAamp Viral RNA Mini Kit (QIAGEN 
$\mathrm{GmbH}$, Hilden, Germany) according to the manufacturer's instructions.

\section{Oligonucleotide primers}

Primers Vv-fp775 (forward primer, 5'-AATTCTCATCACAGTACCAAG-3') and Vv-rp1028 (reverse primer, 5'-GCTGGTTGGAATCACAAT-3') specific for a $254 \mathrm{bp}$ sequence located at nucleotide position 775 to 1,028 of VP2 hypervariable region of segment A of serotype 1 IBDV genome were used in RT-PCR. These primers were originally designed and used by Kusk et al(2005) for detection of IBDV.

\section{RT-PCR}

RNAs from bursal samples, embryo suspension and reference IBDVs were reverse transcribed to cDNA and amplified by a one-step RT-PCR (Ikuta et al, 2001) in $50 \mu \mathrm{l}$ of reaction mixture containing $5 \mu \mathrm{l}$ of $10 \times$ LA buffer, $2 \mu \mathrm{l}$ of $10 \mathrm{mM}$ dNTP, $2 \mu \mathrm{l}$ of $25 \mathrm{mM} \mathrm{MgCl}_{2}$, $1 \mu \mathrm{l}$ prime RNase inhibitor, $0.3 \mu \mathrm{l}$ AMV-RT, $1 \mu \mathrm{l}$ of each primer, $13 \mu \mathrm{l}$ RNA, $0.2 \mu \mathrm{l}$ LA-Taq DNA polymerase and $24.5 \mu \mathrm{l}$ DEPC water. Initially, $13 \mu \mathrm{l}$ of RNA and required amount of DEPC water were taken in a PCR tube, mixed and placed on thermocycler (MJ Mini Thermocycler, Bio-Rad, USA), heated at $68^{\circ} \mathrm{C}$ for $5 \mathrm{~min}$ for initial denaturation of double stranded RNA followed by snap cooling on ice. Then reaction mixture was added to PCR tube, mixed gently and returned to thermocycler. Reverse transcription was performed at $42^{\circ} \mathrm{C}$ for $1 \mathrm{hr}$ followed by activation of $\mathrm{Taq}$ polymerase at $94^{\circ} \mathrm{C}$ for $2 \mathrm{~min}$, then 39 cycles of denaturation at $94^{\circ} \mathrm{C}$ for $30 \mathrm{sec}$, annealing at $45^{\circ} \mathrm{C}$ for $1 \mathrm{~min}$ and elongation at $60^{\circ} \mathrm{C}$ for $1.5 \mathrm{~min}$. A final extension step was performed at $60^{\circ} \mathrm{C}$ for $10 \mathrm{~min}$. After amplification, RT-PCR product was subjected to electrophoresis on $2 \%$ agarose gel containing ethidium bromide $(5 \mu \mathrm{g} / \mathrm{ml})$. The resulting band was examined under UV-transilluminator.

\section{RESULTS}

\section{Isolation of IBDV in chicken embryos}

Out of 35 bursal samples, 28 (80\%) were found positive for virus isolation. Mortality of the embryos started $48 \mathrm{hr}$ postinoculation (PI) and 20 60\% embryos died within 5 days of PI. The dead embryos were edematous with cutaneous congestion and had some petechial hemorrhages. Thickening of the CAMs was observed in most cases. The isolates from three outbreaks of Mymensingh district were designated as BML-2/07, BML-8/07 and BMB-11/07, and those of two outbreaks of Chittagong district were designated as BCB-13/07 and BCL$14 / 07$ and the isolates of two outbreaks of Tangail district were named as BTB-4/07 and BTB-5/07 respectively.

\section{AGIDT}

By AGIDT, 32 (91.4\%) bursal samples were found positive for IBDV. Prominent line of precipitation was noticed between known positive anti-IBDV hyperimmune serum of the central well and bursal homogenates of the peripheral wells due to antigen and antibody reaction within $24 \sim 48 \mathrm{hr}$. The pattern of precipitation lines indicated that IBDVs detected in 29 bursal samples of six affected farms were identical to each
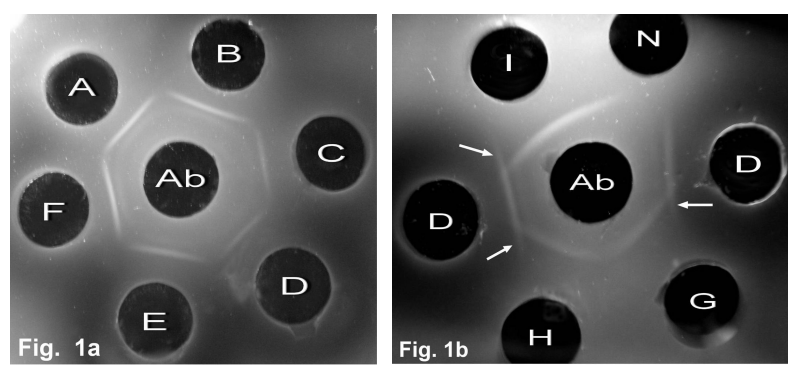

Fig. 1. Agar gel immunodiffusion test demonstrating the presence of IBDV in bursal samples of affected chickens. Ab: Known hyperimmune serum against IBDV, A: BML-2/07 isolate, B: BML-8/07 isolate, C: BCB-13/07 isolate, D: BCL-14/07 isolate, E: BTB-4/07 isolate, F: BTB-5/07 isolate, G: BMB-11/07 isolate, H: Positive control (Nobilis ${ }^{\mathbb{R}}$ Gumboro $228 \mathrm{E}$, Intervet, Netherlands), I: BAU 404 vaccine strain (classical strain), N: Negative control (NDV). Arrow indicates spur formation. 
other but were different from BAU 404 vaccine strain (classical strain) and IBDVs present in the remaining three samples of another farm (Fig. 1). However, IBDVs present in these three samples showed a line of complete identity with the reference IBDV antigens Nobilis ${ }^{\mathrm{R}}$ Gumboro 228E strain. No line of precipitation was observed in $3(8.6 \%)$ samples making them negative for IBDV antigen.

\section{Histopathology}

The lesions typical of IBD were observed in all the 35 bursal samples. Moderate to marked cell depletion,

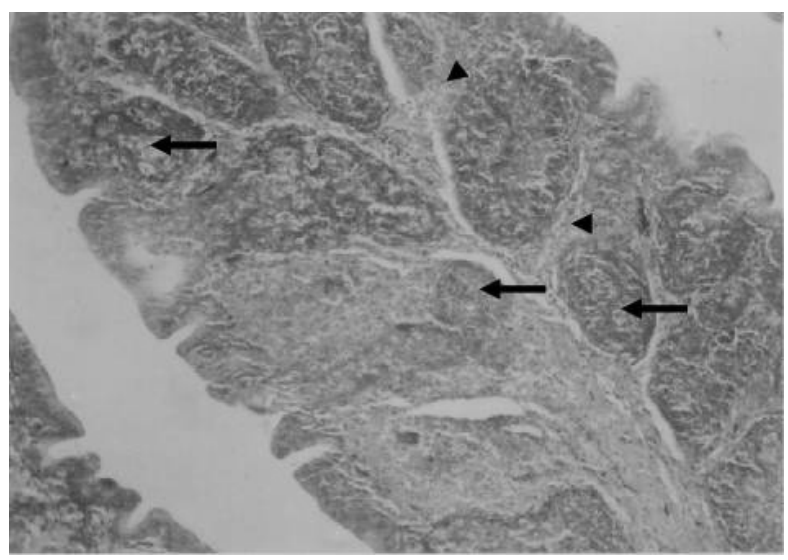

Fig. 2. Section of bursa of Fabricius of 23-day-old broiler chickens naturally infected with IBDV showing follicular atrophy (arrow) and edema of the interfollicular septa (arrow head) (H\&E stain, $\times 82.5)$.

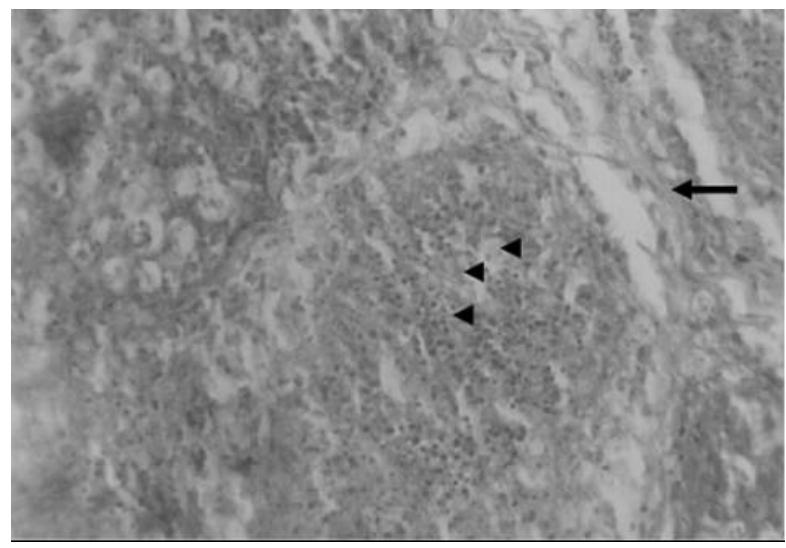

Fig. 3. Section of bursa of Fabricius of 33-day-old layer chickens naturally infected with IBDV showing necrotic follicle with lymphoid cell depletion (arrow head) and edematous interfollicular septa (arrow) (H\&E stain, $\times 330$ ). atrophy and necrosis in many follicles were observed. Severe edema of interfollicular septa was also evident (Fig. 2, Fig. 3).

\section{Immunohistochemistry}

Indirect immunoperoxidase staining of the bursal sections revealed the presence of IBDV antigen in 32 (91.4\%) samples. The IBDV antigen was detected by brown colour deposit with 3, 3 diaminobenzidine (DAB) precipitate in tissue sections. The staining reaction was found mainly in the cortex of the lymphoid follicles (Fig. 4). Positive reactions were absent in bursal sections stained with nonimmune chicken serum and chicken anti-NDV serum in place of chicken anti-IBDV se-

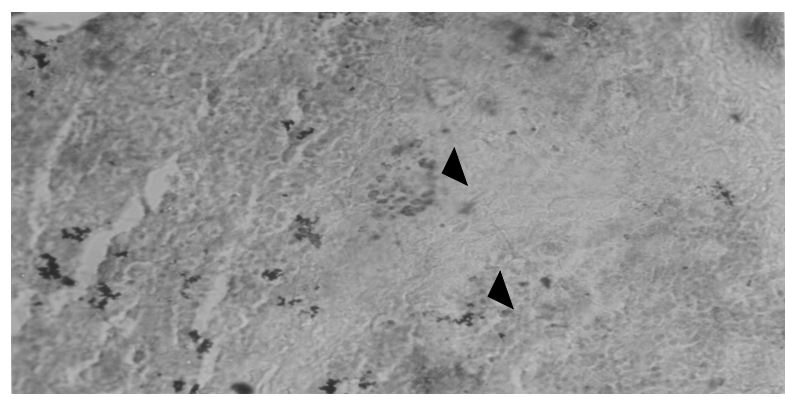

Fig. 4. Section of bursa of Fabricius of 33-day-old layer chickens naturally infected with IBDV showing brown colour materials (IBDV antigens, arrow) following indirect immunoperoxidase staining (H\&E stain, $\times 330$ ).

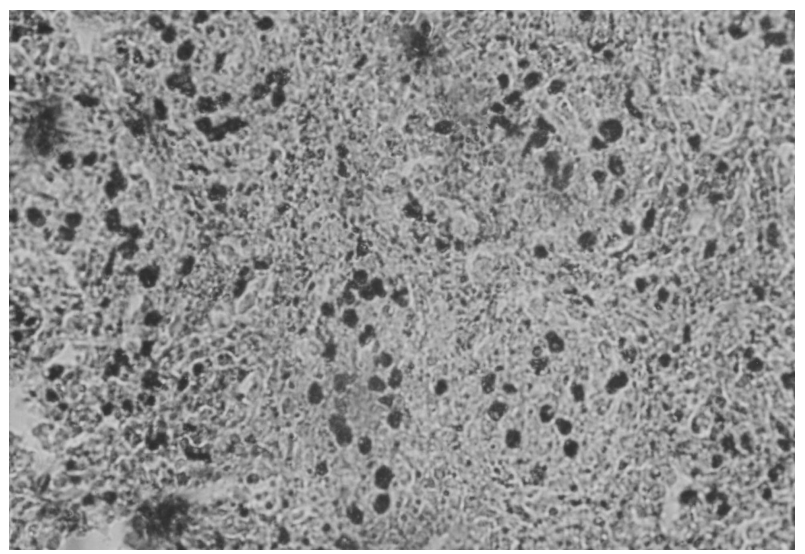

Fig. 5. Section of bursa of Fabricius of 33-day-old layer chickens naturally infected with IBDV showing no brown colour materials (IBDV antigens) following indirect immunoperoxidase staining with chicken anti-NDV serum in place of chicken anti-IBDV serum (H\&E stain, $\times 330$ ). 
rum (Fig. 5).

\section{RT-PCR}

Of the 35 bursal samples, 34 (97.1\%) samples generated $254 \mathrm{bp}$ amplicon by RT-PCR as ascertained by agarose gel electrophoresis (Fig. 6). One (2.9\%) sample was negative for IBDV showing no amplified product in RT-PCR. Same amplicon size of DNA was also observed by RT-PCR amplification from RNA samples of two vaccine strains of IBDV i.e. BAU 404 (DLS, Dhaka, Bangladeshi) and 228E (Intervet International, Netherlands) as well as of the corresponding embryo suspensions of 28 bursal samples which were positive for virus isolation in chicken embryos (Fig. 7). No amplified products of RT-PCR were detected from the bursal sample of the uninfected control birds.

\section{DISCUSSION}

After the emergence of vvIBDV strains among the poultry population of Bangladesh (Islam et al, 2001), there were some sporadic outbreaks of IBD in commercial flocks in Bangladesh (Islam and Samad, 2003). However, acute IBD has not been reported for some years since 2003. In 2007, many outbreaks of acute IBD throughout the country have caused concern in the

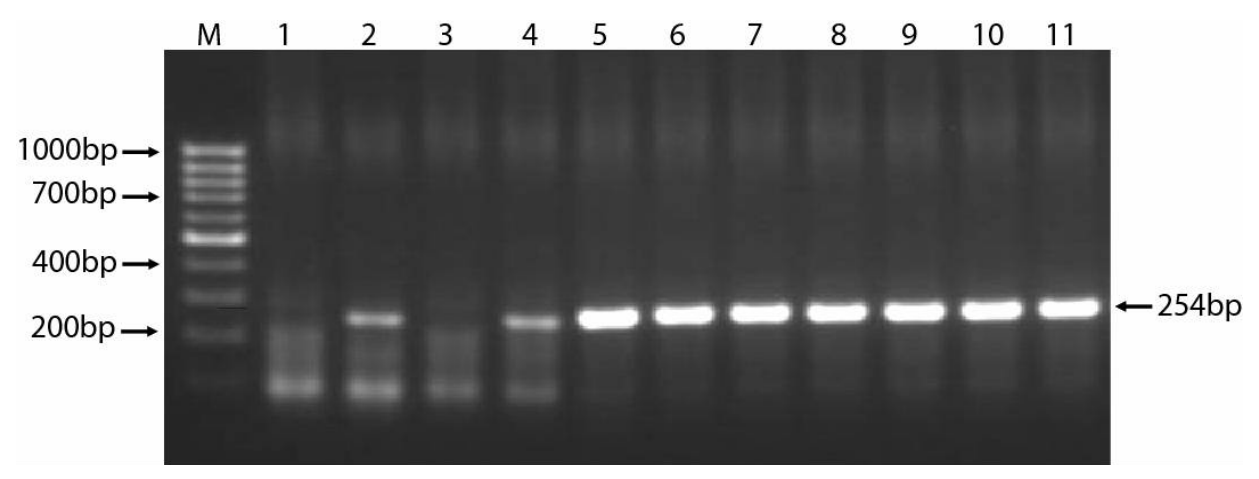

Fig. 6. RT-PCR amplified products from bursa of Fabricius following $2 \%$ agarose gel electrophoresis and ethidium bromide staining. M: DNA marker (100 bp), lane 1: Negative control (bursal suspension negative for IBDV), lane 2: Positive control (BAU 404, DLS, Dhaka), lane 3: Negative control (NDV), lane 4: Positivecontrol (Nobilis ${ }^{\circledR}$ Gumboro 228E, Intervet), lane 5: BML-2/07 isolate, lane 6: BML-8/07 isolate, lane 7: BMB-11/07 isolate, lane 8: BCB-13/07 isolate, lane 9: BCL-14/07 isolate, lane 10: BTB-4/07 isolate, lane 11: BTB-5/07 isolate.

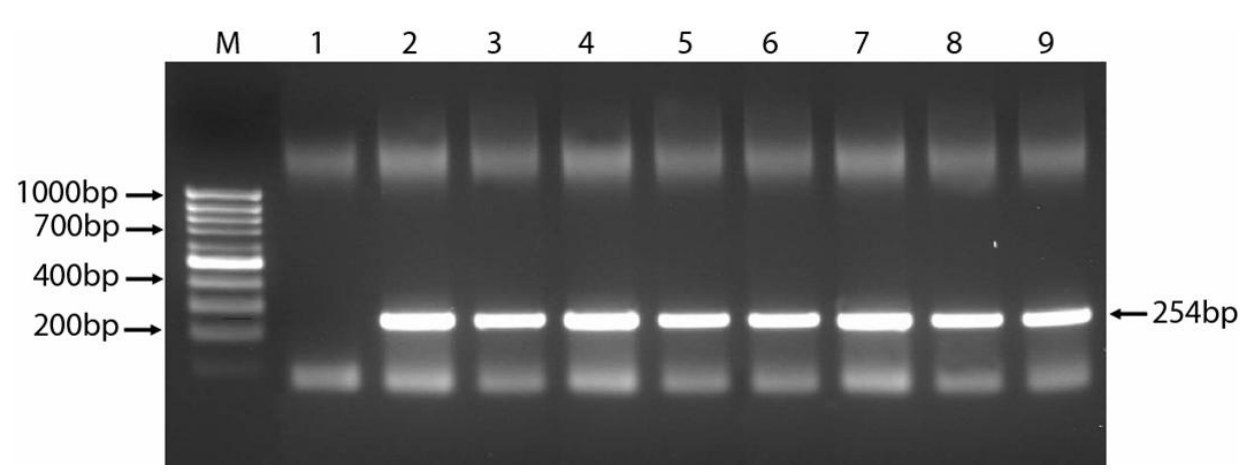

Fig. 7. RT-PCR amplified products from isolates from embryo inoculation following $2 \%$ agarose gel electrophoresis and ethidium bromide staining. M: DNA marker (100 bp), lane 1: Negative control (bursal suspension negative for IBDV), lane 2: Positive control (Nobilis ${ }^{\circledR}$ Gumboro 228E, Intervet), lane 3: BML-2/07 isolate, lane 4: BML-8/07 isolate, lane 5: BMB-11/07 isolate, lane 6: BCB-13/07 isolate, lane 7: BCL-14/07 isolate, lane 8: BTB-4/07 isolate, lane 9: BTB-5/07 isolate. 
poultry industry. The present study reports the isolation and identification of IBDVs circulating in the field that caused acute outbreaks of IBD in four broiler and three layer farms during the year 2007.

In the present study, 9-day-old embryonated chicken eggs were used for isolation of viruses and $28(80 \%)$ bursal samples were found positive for IBDV using eggs from seronegative birds. The rate of isolation of viruses could be higher if SPF eggs were used. The viruses induced $20 \sim 60 \%$ mortality within $2 \sim 5$ days of PI, with lesions similar to those described earlier (Rosales et al, 1989; Abdel-Alim and Saif, 2001). Abdel-Alim and Saif (2001) reported $100 \%$ mortality of SPF embryos within $3 \sim 4$ days of PI with very virulent strains of IBDV.

The presence of IBDV antigen was confirmed in 32 (91.4\%) bursal samples by AGIDT. The higher rate ( $>80 \%$ ) of detection of IBDV by AGIDT was reported by Nachimuthu et al(1995). AGIDT clearly indicated that IBDVs of six outbreaks were identical to each other but not to IBDVs of another one outbreak and BAU 404 vaccine strain (classical strain) as they formed spurs at the junction between the lines of precipitation. However, IBDVs of that outbreak were identical to Nobilis ${ }^{\circledR}$ Gumboro $228 \mathrm{E}$ vaccine strain which led to assume that there might have occurred vaccine failure. AGIDT has been reported by a number of workers to be useful in easy screening of the field samples, prior to either isolation of the virus or to applying other techniques for virus detection and characterization (Rosales et al, 1989; Kadam and Jhala, 2003).

Histological changes observed in all the bursal sections were similar to the observations of Rosales et al (1989) and Hassan et al(1996). Moderate to severe bursal atrophy because of lymphoid cell depletion observed in this study may be indicative of classical or highly virulent nature of IBDVs as reported earlier (Sharma et al, 1989). Diagnosis of IBDV infections using histopathology is not always reliable, because other infectious and non-infectious agents can cause bursal atrophy (Riddell, 1987) as well. Therefore, immunohistochemical demonstration of viral antigen may be useful for differential diagnosis (Cruz-Coy et al, 1993). In the present study, 32 (91.4\%) samples were found positive for IBDV by immunohistochemistry. IBDV antigens were detected mainly in the cortical portion of the bursal follicle. The results correlated well with the immunoperoxidase detection of IBDV antigen from bursal samples of IBD affected chickens as reported previously by earlier workers (Jonsson and Engstrom, 1986; Tanimura et al, 1995).

Thirty four (97.1\%) bursal samples and the positive control samples produced amplicon of approximately 254 bp as expected with Vv-fp775 and Vv-rp1028 primer pair by RT-PCR. Kusk et al (2005) has also successfully targeted the same gene sequences using the same primer pair used in the present study. The application of RT-PCR as a tool for the diagnosis of IBDV infection has been widely reported (Wu et al, 1992; Kabell et al, 2005).

In conclusion, results of isolation and identification by AGIDT, IHC and the analysis of viral genome by RT-PCR confirmed the recent outbreaks of IBD in commercial poultry of Bangladesh. Moreover, histopathological findings and results of AGIDT gave a clear indication that the isolates of six outbreaks were different from classical strain and seems to be of very virulent strain. On the other hand, the isolates from the other outbreak seems to of classical strain. Further research on characterization of the isolates of IBDV of Bangladesh at molecular level by nucleotide sequencing of hypervariable region of the VP2 gene in order to determine the possible emergence of IBDV strains with modified antigenic and/or virulence properties is in progress.

\section{ACKNOWLEDGMENTS}

The authors would like to acknowledge the financial assistance of the FnF Pharmaceuticals Ltd., Jhenidah, Bangladesh to conduct this research. We thank Dr. Nabiul Islam, Department of Anatomy and Histology, BAU, Mymensingh for performing the immunohistochemical analysis.

\section{REFERENCES}

Abdel-Alim GA, Saif YM. 2001. Immunogenicity and anti- 
genicity of very virulent strains of infectious bursal disease viruses. Avian Dis 45: 92-101.

Chettle N, Stuart JC, Wyeth PJ. 1989. Outbreak of virulent infectious bursal disease in East Anglia. Vet Rec 125: 271-272.

Cruz-Coy JS, Giambrone JJ, Hoerr FJ. 1993. Immunohistochemical detection of infectious bursal disease virus in formalin-fixed, paraffin-embedded chicken tissues using monoclonal antibody. Avian Dis 37: 577-581.

Faragher JT, Allan WH, Wyeth PJ. 1974. Immunosuppressive effect of infectious bursal agent in vaccination against Newcastle disease. Vet Rec 95: 385-388.

Hassan MK, Al-Natour MQ, Ward LA, Saif YM. 1996. Pathogenicity, attenuation, and immunogenicity of infectious bursal disease virus. Avian Dis 40: 567-571.

Hudson PJ, McKern NM, Power BE, Azad AA. 1986. Genomic structure of the large RNA segment of infectious bursal disease virus. Nucl Acids Res 14: 5001-5012.

Ikuta N, El-Attrache J, Villegas P, García EM, Lunge VR, Fonseca AS, Oliveira C, Marques EK. 2001. Molecular characterization of Brazilian infectious bursal disease viruses. Avian Dis 45: 297-306.

Islam MR, Zierenberg K, Eterradossi N, Toquin D, Rivallan G, Müller H. 2001. Molecular and antigenic characterization of Bangladeshi isolates of infectious bursal disease virus demonstrates their similarities with recent European, Asian and African very virulent strains. J Vet Med B Infect Dis Vet Public Health 48: 211-221.

Islam MT, Samad MA. 2003. Outbreaks of infectious bursal disease in vaccinated and unvaccinated commercial cockerel farms in Bangladesh. Bangl $\mathrm{J}$ Vet Med 1: 21-24.

Islam MT, Islam MA, Samad MA. 2005. Immunosuppressive effect of infectious bursal disease virus and vaccine on humoral immune response of broiler chickens to Newcastle disease vaccination. Progress Agric 16: 71-75.

Jackwood DJ, Saif YM, Moorhead PD. 1985. Immunogenicity and antigenicity of infectious bursal disease virus serotypes I and II in chickens. Avian Dis 29: 1184-1194.

Jackwood DJ, Saif YM. 1987. Antigenic diversity of infectious bursal disease viruses. Avian Dis 31: 766-770.

Jackwood DJ, Sommer-Wagner SE. 2005. Molecular epidemiology of infectious bursal disease viruses: distribution and genetic analysis of newly emerging viruses in the United States. Avian Dis 49: 220-226.

Jonsson LG, Engstrom BE. 1986. Immunohistochemical detection of infectious bursal disease and infectious bronchitis viral antigens in fixed, paraffin-embedded chicken tissues. Avian Pathol 15: 385-393.

Kabell S, Handberg KJ, Li Y, Kusk M, Bisgaard M. 2005. Detection of vvIBDV in vaccinated SPF chickens. Acta Vet Scand 46: 219-227.

Kadam M, Jhala MK. 2003. Comparison of serological tests for detection of infectious bursal disease virus in bursal samples. Indian Vet J 80: 723-726.
Kusk M, Kebell S, Jorgensen PH, Handberg KJ. 2005. Differentiation of five strains of infectious bursal disease virus: development of a strain specific multiplex PCR. Vet Microbiol 109: 159-167.

Leong JC, Brown D, Dobos P, Kibenge F, Ludert JE, Müller H, Mundt E, Nicholoson B. 2000. Birnaviridae. pp. 481-490. In: van Regenmortel MHV, Fauquet CM, Bishop DHL, Carstens EB, Estes MK, Lemon SM, Maniloff J, Mayo MA, McGeoch DJ, Pringle CR, Wickner RB(ed.). Virus taxonomy: classification and nomenclature of viruses. Seventh report of the International Committee on Taxonomy of Viruses. Academic Press, San Diego, Califonia.

Luna LG. 1968. Manual of Histologic Staining Methods of the Armed Forces Institute of Pathology. pp. 121-123. 3rd ed. McGraw-Hill Book Co, New York.

Müller H, Islam MR, Raue R. 2003. Research on infectious bursal disease - the past, the present and the future. Vet Microbiol 97: 153-165.

Müller R, Käufer I, Reinacher M, Weiss E. 1979. Immunofluorescent studies of early virus propagation after oral infection with infectious bursal disease virus (IBDV). Zentralbl Veterinarmed B 26: 345-352.

Nachimuthu K, Raj GD, Thangavelu A, Venkatesan RA. 1995. Reverse passive haemagglutination test in the diagnosis of infectious bursal disease. Trop Anim Health Prod 27: 43-46.

Rahman MM, Hossain WIMA, Rahman MM, Miah AH, Biswas MHR. 1996. Isolation and identification of infectious bursal disease virus in chickens in Bangladesh. Bangl Vet J 30: 7-11.

Riddell C. 1987. Avian Histopathology. pp. 1-17. American Association of Avian Pathologists. Kennett Square, Pennsylvania.

Rosales AG, Villegas P, Lukert PD, Fletcher OJ, Mohamed MA, Brown J. 1989. Isolation, identification and pathogenicity of two field strains of infectious bursal disease virus. Avian Dis 33: 35-41.

Sharma JM, Dohms JE, Metz AL. 1989. Comparative pathogenesis of serotype 1 and variant serotype 1 isolates of infectious bursal disease virus and their effect on humoral and cellular immune competence of specific-pathogen-free chickens. Avian Dis 33: 112-124.

Spies U, Müller H, Becht H. 1987. Properties of RNA polymerase activity associated with infectious bursal disease virus and characterization of its reaction products. Virus Res 8: 127-140.

Tanimura N, Tsukamoto K, Nakamura K, Narita M, Maeda M. 1995. Association between pathogenicity of infectious bursal disease virus and viral antigen distribution detected by immunohistochemistry. Avian Dis 39: 9-20.

Van den Berg TP, Gonze M, Meulemans G. 1991. Acute infectious bursal disease in poultry: Isolation and characterization of a highly virulent strain. Avian Pathol 20: 133-143.

Wood GW, Muskett JC, Herbert CN, Thornton DH. 1979. 
Standardization of the quantitative agar gel precipitation test for antibodies to infectious bursal disease. J Biol Stand 7: 89-96.
Wu CC, Lin TL, Zhang HG, Davis VS, Boyle JA. 1992. Molecular detection of infectious bursal disease virus by polymerase chain reaction. Avian Dis 36: 221-226. 